\title{
First report of maize striate mosaic virus (Geminiviridae) in sugarcane (Saccharum officinarum)
}

\author{
J. G. Batista ${ }^{1}$ - L. S. Boiteux ${ }^{1,2}$ - F. F. S. Melo ${ }^{1}$ - B. E. C. Miranda ${ }^{1}$ S. G. Ribeiro ${ }^{3}$ M. E. N. Fonseca ${ }^{2} \cdot$ R. C. Pereira- \\ Carvalho $^{1}$ (D)
}

Received: 21 March 2021 / Accepted: 18 May 2021 / Published online: 24 June 2021

(c) Australasian Plant Pathology Society Inc. 2021

\begin{abstract}
Maize striate mosaic virus (MSMV; genus Mastrevirus) has been previously reported in association with maize in Brazil. Here, we recovered the complete genome of a novel MSMV isolate from sugarcane via high-throughput sequencing. PCR assays with MSMV specific-primers confirmed the presence of this virus in sugarcane. To our knowledge, this is the first worldwide report of MSMV on sugarcane.
\end{abstract}

Keywords Sugarcane $\cdot$ High-throughput sequencing $\cdot$ Mastrevirus

Brazil is currently the leading country in sugar and ethanol production from sugarcane (Saccharum officinarum L.). This crop is affected by many virus-induced diseases responsible for severe yield losses worldwide (Gonçalves et al. 2012). Members of the genus Mastrevirus (family Geminiviridae) exhibit monopartite genomes and are efficiently transmitted by leafhoppers (order Hemiptera, family Cicadellidae). Mastreviruses have widespread geographical distribution across major sugarcane-producing regions in Africa and Asia, with eight viruses reported infecting this crop thus far (Boukari et al. 2017; 2020). Recently, a new mastrevirus - maize striate mosaic virus (MSMV) - was described in association with maize (Zea mays L.) and adult leafhoppers (Dalbulus maidis DeLong and Wolcott) in Central Brazil (Fontenele et al. 2018). During field surveys conducted in 2016 and 2018 , five sugarcane leaf samples displaying mild chlorotic streak and 14 maize leaf samples with striate mosaic symptoms (Fig. 1a, b) were collected in Brasília (Estação Experimental de Brasília - EEB and Fazenda Água Limpa - FAL) and Planaltina (Instituto Phytus) in the Federal

R. C. Pereira-Carvalho

rcpcarvalho@unb.br

1 Dept. Fitopatologia, Universidade de Brasília (UnB), Brasília, DF, Brazil

2 Embrapa Hortaliças (CNPH), Brasília, DF, Brazil

3 Embrapa Recursos Genéticos e Biotecnologia, Brasília, DF, Brazil
District (DF), Central Brazil. The prevalence of these symptoms was about $50 \%$ in both crops. Total genomic DNA was extracted from each sample using a modified CTAB method (Boiteux et al. 1999). Purified DNA was used as a template in rolling-circle amplification (RCA) assays using Phi-DNA polymerase (Inoue-Nagata et al. 2004). Afterward, RCA products were pooled and sequenced in an Illumina Hi-Seq 2500 platform at Macrogen Inc. (South Korea), using a Nextera DNA Library Prep kit. The sequencing generated 29,882,284 paired-end reads, which were assembled with CLC Genomic Workbench 9.0 version (Qiagen Bioinformatics) resulting in 54,923 contigs. Contigs were compared with a local viral RefSeq database using BLASTn and BLASTx algorithms in Geneious ${ }^{\circledR} \mathrm{R} 11$. A circular contig (with 2,746 nucleotides) was identified, displaying identities higher than $99 \%$ with MSMV isolates from maize (MF167297-MF167307). For the recovery of the full-length genome of MSMV, PCR assays in conjunction with Sanger dideoxy sequencing were employed. In addition, a pair of abutting primers (J455-F, 5'-ACC CTT CTT AAC TTC CAC CAC GGC AGA A-3' and J455-R, 5'-GGT AAT TGT CTG ATG GTT ACC TCC TAC A-3') were used in PCR assays essentially as described by Fontenele et al. (2018), using as template the total DNA extracted from all five sugarcane and 14 maize samples. MSMV-derived amplicons $(\approx 2,700 \mathrm{~kb})$ were obtained from two maize and two sugarcane samples. These amplicons were purified and sequenced at Myleus (Minas Gerais, Brazil). The complete genome (2,746 bp) of one sugarcane MSMV isolate 
Fig. 1 a Mild chlorotic streak symptoms in a sugarcane (Sacharum officinarum L.) leaf infected with maize striate mosaic virus (MSMV), b Diagrammatic illustration of the genome (2,746 nucleotides) of a MSMV isolate from sugarcane (MN535988), displaying four ORFs (open reading frames) with structural genomic features typical of the mastreviruses, Rep and REpA replicase (C1:C2), MP movement protein (V2) and $C P$ Coat Protein (V1) a

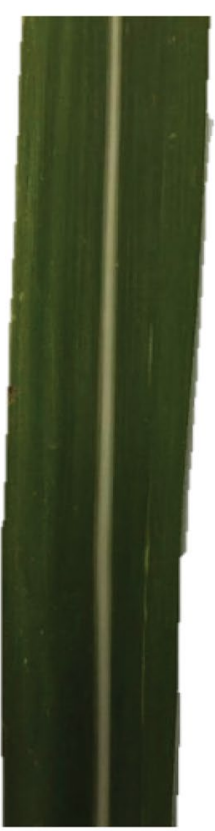

b

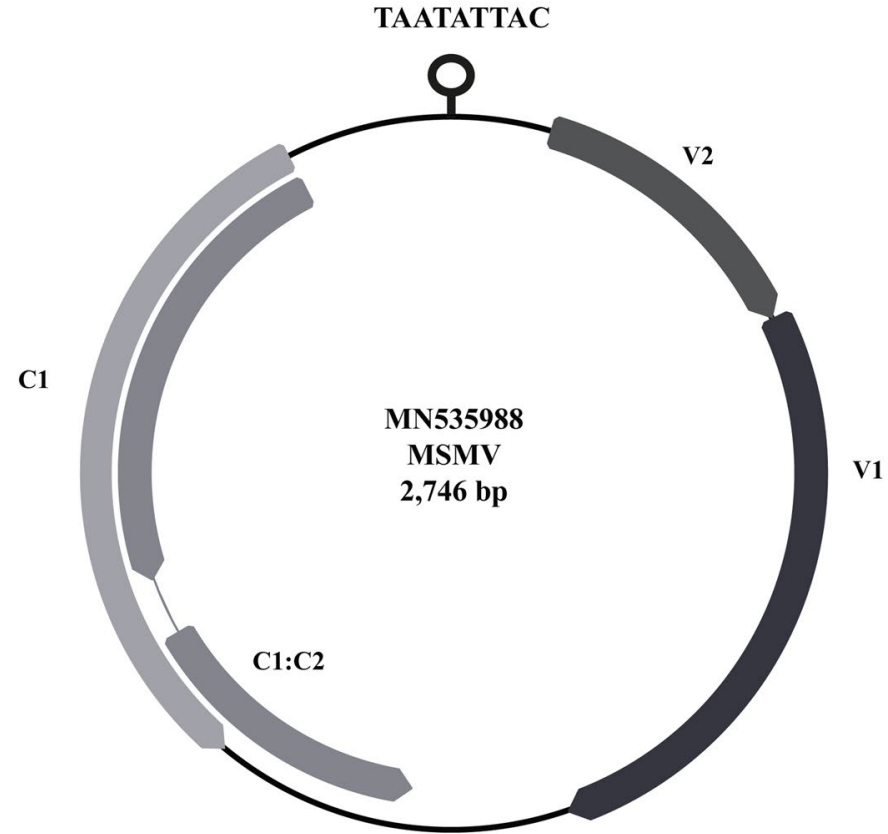

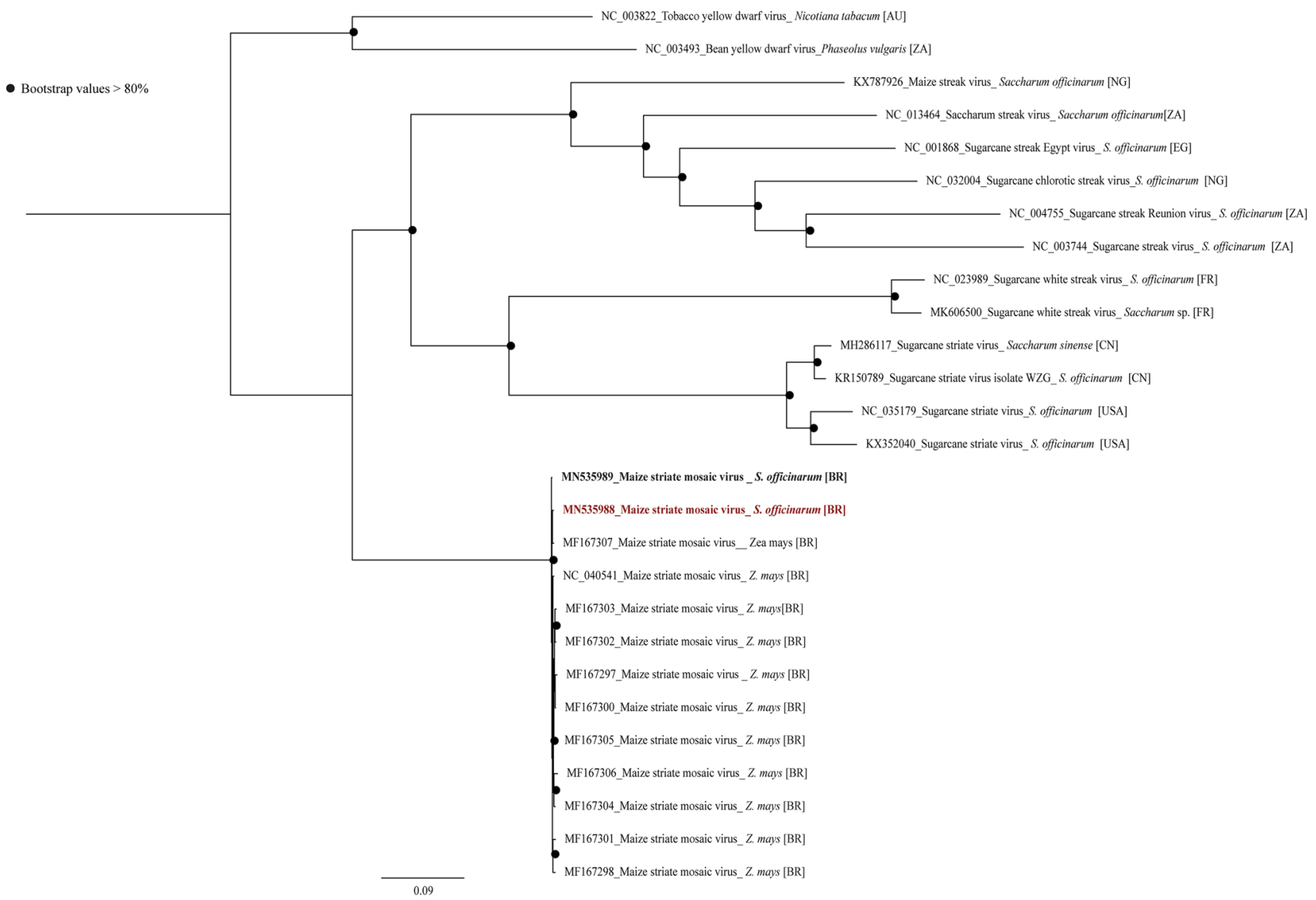

Fig. 2 Phylogenetic relationship (neighbor-joining method) based on DNA viral sequences of maize striate mosaic virus (MSMV) (the both MSMV isolates in bold red and black are from sugarcane) with other mastreviruses. Sequences were aligned using Geneious.
The sequence of the maize striate mosaic virus (MF167307 isolate) was obtained from Dalbulus maidis. The scale bar indicates pairwise nucleotide distance. Tobacco yellow dwarf virus (NC_003822) and Bean yellow dwarf virus (NC_003493) were used as outgroup 
(MN535988) was recovered and displayed four ORFs (open reading frames) with structural genomic features typical of mastreviruses. In the viral sense were annotated the V1 gene (codifying the coat protein - CP) and the V2 gene (movement protein - MP) (Fig. 1b), while in the complementary sense the $\mathrm{C} 1$ (replication-associated protein - RepA) and the $\mathrm{C} 1: \mathrm{C} 2$ (Rep) genes were identified. All gene products of the MSMV isolate from sugarcane displayed sequences identities $\geq 99 \%$ to other maize-infecting MSMV isolates available at the GenBank. A neighbor-joining (NJ) phylogenetic tree (algorithm MUSCLE, number of bootstrap replications: 1,000$)$ was constructed based upon complete mastrevirus sequences using Geneious (Kearse et al. 2012) and all MSMV sequences were grouped in a single clade (Fig. 2). The close genomic relationship among MSMV sequences from maize and sugarcane in Central Brazil strongly suggest that these isolates might share a common origin. Sugarcane is a vegetatively propagated crop with longer life cycle in comparison with maize, which is a seasonal crop. Therefore, it can be hypothesized that sugarcane is most likely the overwintering natural reservoir of this virus under field conditions. To our knowledge, this is the first description of MSMV on sugarcane. The potential impacts of MSMV infection in sugarcane and maize are yet to be determined. However, since sugarcane crop is maintained by vegetative propagation of elite clones, it favors long-term virus maintenance under field conditions. The detection of MSMV in sugarcane and maize plants could represent an alert to the sugarcane and maize producers to monitor its impact on sugarcane growth and production, especially when planted next to maize.

Acknowledgements The authors would like to thank Fernando L. Melo.

Funding Financial support was provided by grants from Embrapa (Empresa Brasileira de Pesquisa Agropecuária), CNPq (Conselho Nacional de Desenvolvimento Científico e Tecnológico) and FAP-DF (Fundação de Apoio à Pesquisa do Distrito Federal). This study was also financed in part by the Brazilian Coordenação de Aperfeiçoamento de Pessoal de Nível Superior (CAPES), finance code 1.

\section{Declarations}

Ethical approval This research does not contain any studies with human participants or animals performed by any of the authors.

Conflict of interest The authors declare that they have no conflict of interest.

\section{References}

Boiteux LS, Fonseca MEN, Simon PW (1999) Effects of plant tissue and DNA purification method on randomly amplified polymorphic DNA-based genetic fingerprinting analysis in carrot. J Am Soc Hort Sci 124:32

Boukari W, Alcalá-Briseño RI, Kraberger S, Fernandez E, Filloux D, Daugrois JH, Roumagnac P (2017) Occurrence of a novel mastrevirus in sugarcane germplasm collections in Florida, Guadeloupe and Réunion. Virol J 14:116

Boukari W, Filloux D, Daugrois J-H, Fernandez E, Mollov D, Kaye C, Hincapie M, Sanchez A, Wang J, Roumangac P, Rott P (2020) Molecular detection of sugarcane striate virus and sugarcane white streak virus and their prevalence in the Miami World Collection of sugarcane and related grasses. Plant Pathol 69:1060. https://doi.org/10.1111/ppa.13192

Fontenele RS, Alves-Freitas DM, Silva PI, Foresti J, Silva PR, Godinho MT, Ribeiro SG (2018) Discovery of the first maize-infecting mastrevirus in the Americas using a vector-enabled metagenomics approach. Arch Virol 163:263

Gonçalves MC, Pinto LR, Souza SC, Landell MGA (2012) Virus diseases of sugarcane. A constant challenge to sugarcane breeding in Brazil. Funct Plant Sci Biotech 6:108-116

Inoue-Nagata AK, Albuquerque LC, Rocha WB, Nagata T (2004) A simple method for cloning the complete begomovirus genome using the bacteriophage $\varphi 29$ DNA polymerase. J Virol Meth 116:209

Kearse M, Moir R, Wilson A, Stones-Havas S, Cheung M, Sturrock S, Buxton S, Cooper A, Markowitz S, Duran C (2012) Geneious Basic: an integrated and extendable desktop software platform for the organization and analysis of sequence data. Bioinformatics 28:1647-1649 